\title{
PIBID DE MÚSICA: UMA EXPERIÊNCIA DA PRÁTICA DOCENTE E DA INSERÇÃO MUSICAL NO ENSINO BÁSICO DE UMA ESCOLA PÚBLICA
}

Cássio Henrique Martins ${ }^{1}$ André de Araújo Leal ${ }^{2}$ Janaina Lima da Silveira ${ }^{3}$ Juniel Pereira da Silva

\section{INTRODUÇÃO}

Este trabalho ${ }^{5}$ constitui-se de um relato de experiência vivido por alguns bolsistas do Programa de Bolsas de Iniciação à Docência (PIBID), financiado pela Coordenação de Aperfeiçoamento de Pessoal de Nível Superior - CAPES, no CETI Prof. Darcy Araújo em Teresina - PI, da área de Música, sendo os mesmos, alunos do curso de música da Universidade Federal do Piauí (UFPI). O Programa (PIBID) deu início, na instituição de ensino mencionada, em setembro de 2012, tendo como bolsistas 10 acadêmicos do Curso de Licenciatura em Música da UFPI.

Segundo Araújo (2006), os saberes brotam da experiência e são validados pela mesma no exercício prático da profissão, e seguindo esta linha norteadora é possível perceber a importância da vivência e participação ativa de acadêmicos licenciandos, na prática docente.

Com a aprovação da Lei $n^{\circ} 11.769 / 2008^{6}$ (BRASIL, 2008), que torna o conteúdo de Música obrigatório, contudo não exclusivo, do componente curricular da

1 Professor Adjunto III, da Universidade Federal do Piauí. Doutorando em Educação, pela Universidade de São Paulo (USP/SP). Email: cassiomartins@ufpi.edu.br

${ }^{2}$ Licenciando em Música, pela Universidade Federal do Piauí. Especializando em Musicoterapia.

Professor de violão. Email: andrelealv1@gmail.com

${ }^{3}$ Licenciando em Música, pela Universidade Federal do Piauí. Professora de canto. Email: ninaballet@hotmail.com

${ }^{4}$ Licenciando em Música, pela Universidade Federal do Piauí. Especialização em Docência do Ensino Superior. Mestrando em Educação (PPGEd/UFPI). Professor de Música litúrgica e canto pastoral, no Instituto Católico de Estudos Superiores do Piauí (ICESPI). Email: nieljorginho@hotmail.com

${ }^{5}$ Este artigo possui sua versão original publicada na obra FRANÇA-CARVALHO, A. D.; MARTINS, C. H. R.; CONDE, E. P.; MONTEIRO, H. R. de S. (org.) Estratégias de ensino: propostas multidisciplinares de aprendizagens significativas. Teresina, EDUFPI, 2013.

${ }^{6}$ Altera a Lei no 9.394, de 20 de dezembro de 1996, Lei de Diretrizes e Bases da Educação, para dispor sobre a obrigatoriedade do ensino da música na educação básica. 
disciplina de Artes na Educação Básica, o PIBID Música tem reforçado a necessidade de investimento nesta área de educação musical, tornando-se, assim, um corpulento aliado quando o assunto é o ensino de música nas escolas públicas de nível básico.

O PIBID tem como objetivo principal estabelecer uma relação teórico-prática eficaz, proporcionando, uma formação contínua aos professores da educação básica e, de maneira particular, no que diz respeito à música, seu processo de ensinoaprendizagem e sua relevante participação no desenvolvimento cultural, social e cognitivo.

Para esta comunicação buscamos, então, o propósito de desenvolver um estudo sobre estas experiências da prática docente, visando delinear categorias dessa prática, entendendo e analisando sua atuação, seu processo e seus benefícios tanto a comunidade escolar como aos pibidianos (Bolsistas do PIBID).

\section{A MÚSICA E O CONTEXTO EDUCACIONAL}

A música é um forte elemento presente nas diversas culturas e é capaz de promover o desenvolvimento de características da personalidade dos indivíduos. Ela exige e promove a extroversão na maneira expressiva e vigorosa de tocar, espírito de equipe na prática de conjunto da música, estabilidade emocional, inteligência na interpretação de uma obra musical, e tudo isso são vantagens que uma pessoa obterá em todo o contexto social não se limitando somente a uma prática musical (BASTIAM, 2009).

O ensino de música na escola regular ganha novos horizontes a partir da Lei no 11769/2008 que torna obrigatório o ensino do conteúdo específico de música na disciplina de artes. E, com o sancionamento desta lei, o ensino da música passa a ter uma importância maior dentro da escola.

A supracitada lei que fortalece e torna obrigatório o ensino musical dentro do ambiente escolar, nas concepções de Sobreira (2012) em certos momentos "enfraquecida", sempre esteve presente no ambiente escolar de algumas instituições.

E diante disto, enxergar a música no contexto escolar nos leva a outras reflexões também relevantes nessa discussão, tais como: Que tipo de ensino 
musical deve-se dar ênfase no ambiente de uma educação de ensino público regular? Que habilidades devem ter ou desenvolver os professores que irão atuar nessa área de ensino?

Mesmo após a aprovação, a Lei n. 11769/2008 não dar-se por fim as discussões a cerca da efetivação da mesma, sendo necessários, ainda, muitos esforços para a concretização de um ensino musical significativo, o que para Koellreuter (apud BRITO, 2001) é aquele capaz de contribuir para uma formação integral do ser humano.

E para a concretização de um ensino significativo conforme mencionado anteriormente, o conhecimento teórico é de fundamental importância para a formação docente, e este ganha maior vivacidade quando unido a uma prática que possa proporcionar uma constante reflexão dialética entre esses dois lados: o teórico e o prático. O conhecimento necessita de prática para se efetivar e concretizar as relações de trabalho (FRANZOL, 2006, apud DEL-BEM). E tal encontro proporciona a validação de ambos.

A UFPI através do projeto PIDID de Música atua decisivamente na formação de futuros professores possibilitando aos licenciandos experiências que irão contribuir para sua atuação no mercado de trabalho.

O PIBID é um programa institucional de bolsa de iniciação a docência, e configura-se como um incentivo na formação de professores para a educação básica; objetiva valorizar o magistério, incentivando os estudantes das áreas de licenciaturas, promovendo a qualidade da educação básica. Busca também uma valorização do espaço da escola pública como campo de experiência para construção do conhecimento na formação de professores para a educação básica. Tem a pretensão de "[...] proporcionar aos futuros professores participações em ações, experiências metodológicas e práticas docentes inovadoras, articuladas com a realidade local da escola em que os mesmos encontram-se inseridos." (CARVALHO, 2011, p.18).

O programa é um grande colaborador numa constante busca do crescimento da qualidade da educação pública, visto que o contexto educacional exige um profissional cada vez mais dinâmico e possuidor de competências múltiplas capazes de atender uma demanda cada vez mais diversificada e que apresenta uma acentuada velocidade nas transformações e nos conhecimentos. 
E esta exigência da realidade educacional clama por um educador mediador de aprendizagem, ou seja, um profissional em que seu trabalho requer a integração de uma dupla formação: no campo disciplinar, representado pelos conhecimentos de sua área específica de ensino; e, no campo do "saber ensinar", de conhecimentos teóricos e práticos que possibilitem a mediação pedagógica de aprendizagem ao saber (CARVALHO, 2011, p.7). E deste modo, não basta somente o professor ter o domínio técnico de sua disciplina, este deve encontrar-se aliado a outros domínios capazes de levar este conhecimento ao seu aluno.

\section{APRESENTAÇÕES MUSICAIS: AQUISIÇÃO DE SABERES E HABILIDADES}

Fazer música faz "ecoar" sons e sonoridades por todos os locais do ambiente em que a música é produzida, e fazer música na escola não é diferente, o som se propaga na sala de aula, passa pelo pátio, volteia o refeitório. Não há um local ou pessoa (seja ela, aluna, professor ou funcionário) que não sinta a vibração destas ondas sonoras, a escola assiste a uma grande movimentação de jovens engajados em seus grupos na produção e execução musical, e este ouvir, sentir e assistir ultrapassa os tão somente sentidos físicos.

Durante o desenvolvimento do PIBID de Música na escola, foram discutidos em reuniões com o coordenador de área, os meios e métodos de contextualizar e dinamizar os conteúdos de musicalização e educação musical de forma abrangente e que atraísse toda a comunidade escolar como eixo de Práticas Pedagógicas. Desta forma, são realizadas aulas de introdução do conteúdo musical contextualizado com a disciplina de artes. E, a partir desta instrução, foi sugerido dentre outras, como atividade prática, o Projeto Intercanção, pensado com o objetivo de realizar apresentações artísticas no momento dos intervalos do turno manhã e tarde no CETI Darcy Araújo, Teresina-PI.

No início deste projeto, os conteúdos de musicalização e educação musical lecionados em sala de aula, eram desenvolvidos em aulas paralelas às atividades do eixo de Práticas Pedagógicas do PIBID. As aulas eram realizadas em períodos extraclasses, nos horários em que os alunos que dispunham de horários livres e os utilizavam para estudos na biblioteca. As aulas do Projeto Intercanção, desenvolvidas pelos pibidianos na escola, são prioritariamente práticas, utilizando-se de conteúdos de técnicas vocais, prática de instrumentos e prática de repertório, que 
ao final de cada período são finalizadas com uma apresentação de cada turma nos intervalos matutinos e vespertinos, práticas essas contidas no eixo de Atividades Complementares.

As músicas são escolhidas por meio de votação, e deste modo, selecionados diferentes estilos musicais de canções voltadas para a cultura do estado e de variados artistas da atualidade.

O entrosamento com os alunos é um importante ingrediente, pois vem romper com a timidez e o medo de falar e se expor em público. Nos encontros em sala de aula são realizadas dinâmicas que envolvem a todos como, por exemplo: reconhecimento de sons com o objetivo de exercitar a percepção sonora, com algumas noções de timbres emitidos pelos animais, os instrumentos e por alguns artistas conhecidos. $\mathrm{Na}$ atividade os alunos tinham os olhos vendados e escutavam diversos sons, tendo que fazer o reconhecimento dos mesmos.

Durante os encontros trabalhavam-se pronúncias, noções de tempo e melodia, noção de ritmo, percussão corporal, dança e teatro.

O projeto foi muito bem acolhido pelo corpo docente e discente da escola, e foi notável a evolução do nível de concentração, disposição e organização dos alunos participantes.

\section{PRÁtICAS MUSICAIS E AS AULAS DE MÚSICA: DESENVOLVIMENTO SOCIAL, CULTURAL E COGNITIVO}

A instituição na qual o PIBID está trabalhando é de tempo integral, são cerca de 330 alunos circulando todos os dias, durante o período da manhã e da tarde, na escola, com objetivos e histórias de vida bem distintas.

A atuação do PIBID de Música na escola se dá em três eixos diferentes, porém interligados, são eles: Eixo de práticas pedagógicas, eixo de atividades complementares e eixo de monitoria.

O Eixo de práticas pedagógicas está sendo trabalhado nas turmas do $1^{\circ}$ e $2^{\circ}$ ano do Ensino Médio, onde o conteúdo abordado faz uma ponte com o conteúdo cobrado no atual Exame Nacional do Ensino Médio (ENEM). No eixo de atividades complementares são realizadas oficinas, que tratam do fazer criativo dos alunos, atividades de percepção e vivência sonora distribuídas nas oficinas de canto coral, percussão corporal, práticas instrumentais, confecção de instrumentos, prática em 
conjunto e outras. O eixo de Monitoria é efetuado em aulas de artes da professora supervisora, onde os pibidianos observam e auxiliam a mesma.

As atividades complementares, ou seja, as oficinas, realizadas no Ensino Fundamental I, encontram um público mais aberto, mais receptivo, disposto a aprender e a experimentar o novo, já as realizadas no Ensino Fundamental II, formado, em sua maioria, por alunos na faixa etária entre 12 e 16 anos, sendo eles não inseridos em uma vivência musical pedagógica. Há certa resistência na participação de forma direta nas atividades propostas pelos pibidianos, porém, a parcela de alunos nestas situações é sempre menor que a parcela que participa ativamente destas atividades.

Situações assim provêm, além de diversas situações já vivenciadas por estes alunos, do fato de o único contato destes ser com a música midiática, havendo então uma barreira a outros "tipos musicais". Sabendo então que, segundo Blacking (1987), a música é parte integrante na vida das pessoas, que ela resulta da interação humana, do contexto social e cultural de maneira específica, trabalhamos então com a música no qual os alunos já estão inseridos. A música popular, porém, sem desprezar a música considerada erudita. $E$, esse trabalhar é muito mais do que simplesmente incluir no repertório, é dá sentido, contextualizar, considerando as experiências e saberes musicais adquiridos informalmente por esses alunos. De acordo com Green (2006, 2008), é preciso priorizar a motivação dos alunos, buscando também conectar as aulas com o prazer que eles têm com a música (em suas vidas) fora do ambiente escolar para que possa ser posto um fim na lacuna existente entre a cultura musical própria da vida dos alunos e a que é colocada em sala de aula.

O PIBID de Música pode então, a partir desta contextualização musical, abranger não somente os alunos e o ensinar-aprender musical, mas pode e está rompendo com os limites físicos do espaço de aprendizagem como sala de aula, proporcionando a toda a comunidade escolar, benefícios próprios da educação e do fazer musical de forma direta e indireta.

A Música, dentro do contexto escolar contribui na formação integral do educando, que através das diversas atividades de criação, execução, apreciação e estudos teóricos, proporciona um maior desenvolvimento, porém, essas práticas musicais desenvolvidas no ambiente escolar devem romper o entendimento de um tão somente aprendizado musical, é necessário que se perceba que trata também 
de um processo educacional que pode promover um desenvolvimento de forma mais abrangente na percepção, expressão, decodificação de linguagens e cognição assim como dos significados e sentidos das coisas, desempenhando também diversas funções nesse processo, como proporcionar prazer e divertimento, ensinar e integrar diversas disciplinas, enriquecer a herança cultural, transformar-se em instrumento de expressão, levar à integração de capacidades, modos pessoais de pensar, sentir e agir na busca do conhecimento global, de novas experiências e vivências.

Porém, para que o ensino de música possa ser esse veículo de conhecimento e tenha contribuição para uma visão intercultural e alternativa diante da homogeneização da atual cultura global e tecnológica, se faz necessário ter uma concreta e clara idéia que possa viabilizar ações não desconexas, mas conectadas à vida real. Essa conexão se dá no contato com a própria música, de forma interessante e também prazerosa, sendo pré-requisito ao educador musical do ensino básico público estar sempre preparado para experienciar o novo. (LOUREIRO, 2009)

\section{RESULTADOS/DISCUSSÕES}

A proposta deste artigo enfatiza a necessidade da articulação entre teoria (discurso oficial) e prática (realidade escolar) da atividade docente e dos pibidianos enquanto futuros docentes de música. As proposições discutidas sugerem implicações ligadas ao saber didático, ao fazer artístico, à formação de professores e às políticas públicas que orientam a educação no país. Este trabalho deixa evidente que o mundo contemporâneo exige a formação de professores de música capazes de atuar de forma ampla nas múltiplas realidades que caracterizam o campo da área na atualidade, lidar com os diferentes espaços de educação musical existentes, articular os diversos conhecimentos necessários para a prática docente na área; integrar aspectos práticos e teóricos na ação educativa, e desenvolver estratégias de ensino contextualizadas com a realidade dos alunos e como objetivos da área.

De acordo com a proposta, pudemos observar que as atividades realizadas pelo PIBID de Música no CETI Darcy durante setembro/2012 e maio/2013 trouxe um grande arcabouço tanto para o aprendizado musical dos alunos quanto para a formação acadêmica dos bolsistas como futuros docentes, pois há uma interação, a 
partir da práxis, que leva não somente a uma única vertente de aprendizado, mas diversas, através das experiências aluno-pibidiano, pibidiano-supervisor e pibidianopibidiano.

A oportunidade que o PIBID de Música proporciona tanto aos bolsistas, quanto ao supervisor, como também aos alunos da rede pública, de vivenciar experiências no campo musical e educacional vai além da sala de aula, ele constrói um vasto e fértil campo de pesquisas e práticas pedagógicas.

Através das experiências adquiridas ao longo do programa, as atividades e eventos do programa, foram organizadas gradativamente, distribuídas, algumas semanalmente e outras mensalmente, onde a organização geral de cada uma ficou na responsabilidade de um dos pibidianos.

$\mathrm{Na}$ execução das mesmas, houve diversos desafios: falta de espaços adequados e com estrutura para os ensaios, indisposição de alguns alunos, falta de concentração e de atenção, timidez, horários extras para ensaios, porém, apesar das dificuldades e graças ao empenho dos bolsistas e acolhimento da escola, essas atividades obtiveram resultados superiores aos esperados.

Entre os resultados obtidos, um dos mais significativos foi à experiência de atuar na realidade do contexto escolar, em diversos níveis (Fundamental I, II e Ensino Médio), utilizando-se de uma tradição e vivência musical dentro da escola, porém, sem haver ensino musical. Na escola já havia alguns alunos que tocavam e cantavam, alguns "grupos musicais" formados, porém, grande parte não era familiarizada com a vivência da execução vocal e/ou instrumental, por isso foi e, é necessário observar a metodologia utilizada para que se utilizasse uma dinâmica de inserção e não de exclusão. Através desta experiência foi possível observar a importância da formação de professores, de docentes competentes, que saibam construir pontes, ao invés de muros, entre a realidade do trabalho realizado e as metas estabelecidas, articulando-se sempre a desenvolver competências com metodologias pautadas na teoria-prática e na resolução de situações problemas.

\section{CONSIDERAÇÕES FINAIS}

Em se tratando de um trabalho em andamento, não há dados totalmente conclusivos. Entretanto, a análise parcial dos dados coletados, por meio da verificação das atividades musicais aplicadas, aponta sempre para a importância da 
consideração dos saberes prévios, da sua integração e do desenvolvimento de outros necessários no processo ensino-aprendizagem. E através deste conjunto de experiências, pudemos perceber que mesmo ao finalizar um Curso de Graduação Licenciatura, nunca estamos totalmente preparados para enfrentar o leque de desafios que encontraremos em sala de aula, que os conhecimentos adquiridos, quando distantes da prática, não serão suficientes para assumir o papel de educar, e de fazê-lo musicalmente.

Através do programa (PIBID) houve uma desconstrução de um aprendizado, dos licenciandos, pautado somente na teoria e, durante o decorrer deste processo de aprendizagem docente como pibidianos, é que se está havendo uma construção de saberes aplicando de forma prática e prazerosa a teoria a qual estamos inseridos no ambiente acadêmico.

\section{REFERÊNCIAS}

ARAÚJO, R. C. de. Formação Docente do Professor de Música: Reflexividade, Competências e Saberes. Revista Hodie. Goiânia, v. 6, n. 2, p. 141-152, 2006.

BASTIAM, H. G. Música na escola: a contribuição do ensino da música no aprendizado e no convívio social da criança/ (tradução Paulo F. Valério). São Paulo: Paulinas, 2009. (Coleção Clave de Sol. Série música e educação).

BLACKING, J. A Commonsense View of all Music. Cambridge and New York: Cambridge University Press, 1987.

BRITO, T. A. de. Koellreutter educador: o humano como objetivo da educação musical. São Paulo: Petrópolis, 2001.

CARVALHO, A. D. (org.). O PIBID na formação para o trabalho docente: enfoques pragmáticos. Teresina: EDUFPI, 2011.

DALBEN A. I. L. F.; LOUREIRO, A. M. A. O ensino de música na educação infantil: entre o discurso e a prática. Educação Musical. Anais do XIX Congresso da ANPPOM, Curitiba, p.5-10. 2009.

DEL-BEM, L. Sobre os sentidos do ensino de música na educação básica: uma discussão a partir da lei 11.769/2008. Revista da ABEM, n, 1. p. 110-134. Março. 2009.

FRANÇA-CARVALHO, A. D.; MARTINS, C. H. R.; CONDE, E. P.; MONTEIRO, H. R. de $S$. (org.) Estratégias de ensino: propostas multidisciplinares de aprendizagens significativas. Teresina, EDUFPI, 2013. 
GREEN, L. Music, Informal Learning and the School: A New Classroom Pedagogy. Hampshire: Ash gate, 2008.

Popular music education in and for itself, and for 'other' music: $\overline{c u r r e n t}$ research in the classroom. International Journal of Music Education, vol.24, n.2, p.101- 118, 2006.

SOBREIRA, S.. A disciplinarização do ensino de música. Anais Do II SIMPOM. (Simpósio Brasileiro De Pós-Graduandos Em Música). 2012. 